\title{
QCM Biosensor for Measurement of Glycated Hemoglobin
}

\author{
Miroslav Pohanka \\ Faculty of Military Health Sciences, University of Defence, Trebesska 1575, CZ-500 01 Hradec \\ Kralove, Czech Republic \\ E-mail: miroslav.pohanka@gmail.com
}

doi: $10.20964 / 2019.12 .16$

Received: 24 June 2019 / Accepted: 16 August 2019 / Published: 29 October 2019

In the body, glycated hemoglobin is spontaneously created by a reaction between hemoglobin and glucose. The glycation reaches only minimal scale in health people but it is much higher as the glucose level is increased. It typically serves as a marker in diabetes mellitus. Chromatography, mass spectrometry and immunoassays are the standard methods for glycated hemoglobin measurement in the current clinical praxis. In this work, piezoelectric biosensor is proposed as a tool for glycated hemoglobin measurement. The biosensor contained immobilized antibodies against glycated hemoglobin in a stable film composed from iron oxide nanoparticles. Standard solution of glycated hemoglobin and human blood samples were used for the prepared biosensor characterization. Non glycated hemoglobin and albumin served for interference testing. The biosensor exerted quite good limit of detection highly under expected physiological level: $0.045 \mathrm{mg} / \mathrm{ml}$ and coefficient of determination 0.968 for the assay was achieved. The assay by biosensor fully correlated to standard ELISA (coefficient of determination 0.948). Non-glycated hemoglobin and albumin in concentrations expected in blood or blood plasma did not caused interference in the assay. The piezoelectric biosensor seems to be a promising tool for routine assay of glycated hemoglobin. Due to overall simplicity, no application of specific reagents or sample manipulation, the biosensor can be easily used in field conditions or in the environment of small medical facilities.

Keywords: affinity; antibody; biosensor; biorecognition; blood; diabetes; glucose; glycated hemoglobin; hemoglobin; immunoassay; label free; piezoelectric; quartz crystal microbalance; QCM

\section{FULL TEXT}

(C) 2019 The Authors. Published by ESG (www.electrochemsci.org). This article is an open access article distributed under the terms and conditions of the Creative Commons Attribution license (http://creativecommons.org/licenses/by/4.0/). 